Article

\title{
Geographical Considerations in Site Selection for Small Modular Reactors in Saskatchewan
}

\author{
Raid Almalki ${ }^{1, *}$, Joseph Piwowar ${ }^{2}$ and Julia Siemer ${ }^{2}$ \\ 1 Department of Geography, Umm Al-Qura University, Makkah 21955, Saudi Arabia \\ 2 Department of Geography and Environmental Studies, University of Regina, Regina, SK S4S 0A2, Canada; \\ Joe.Piwowar@uregina.ca (J.P.); Julia.Siemer@uregina.ca (J.S.) \\ * Correspondence: rhmalki@uqu.edu.sa
}

Received: 24 July 2019; Accepted: 13 September 2019; Published: 18 September 2019

check for updates

\begin{abstract}
Saskatchewan is one of Canada's highest emitters of greenhouse gases, largely due to the burning of lignite coal to generate electricity. The province is also the world's second largest producer of uranium. This research was intended to establish a process for evaluating geographical considerations in site selection for small modular reactors (SMRs) in Saskatchewan. SMRs are the next generation of electrical power, producing less than 300 megawatts (MW) and featuring a basic design that offers enhanced safety, health, and environmental benefits compared to traditional reactors. Selecting an SMR site is a two-stage process: (i) Identifying candidate site locations based solely on available geographical, economic, and logistical data-an objective process-and (ii) refining the potential locations based on public perceptions, social conventions, and political will—a subjective process. This study focused on the objective geographical considerations in SMR site selection in Saskatchewan. The study areas were subjected to a multi-criteria decision analysis based on specific criteria drawn from various Canadian federal regulation documents. Criteria weights were assigned using the analytical hierarchy process, with results for two different types of criteria weights applied for the purpose of demonstration. Three distinct cases of criteria fuzzy standardization were conducted to assign spatial suitability values for all the criteria. Spatial decision-making models were implemented in a geographic information system to identify candidate sites. Geographical maps constructed from the findings showed suitable sites for SMRs, ranging from very suitable to unsuitable based on the geographical analysis of the study area.
\end{abstract}

Keywords: Saskatchewan; geographical; small modular reactors; environment; uranium; electricity

\section{Introduction}

The climatic effects of increasing atmospheric $\mathrm{CO}_{2}$ are a widespread concern, influencing decisions about how electricity should be generated. Worldwide releases of $\mathrm{CO}_{2}$ from burning fossil fuels total about 30 billion tonnes per year, with about $40 \%$ from coal and $43 \%$ from oil [1]. Every 1000-MW power station running on black coal produces about 7 million tonnes of $\mathrm{CO}_{2}$ emissions; if brown coal is used, the amount increases to about 9 million tonnes [1].

Saskatchewan generates electricity from a variety of sources. The provincial utility SaskPower operates five gas-powered stations, three coal-fired stations, seven hydroelectric stations, and two wind facilities [2]. These facilities have a generating capacity of $3338 \mathrm{MW}$, with an additional $843 \mathrm{MW}$ available through long-term power purchase agreements [2]. SaskPower's total available capacity is marginally more than the province's record system peak load of $3628 \mathrm{MW}$, set in January 2015 [2]. About $40 \%$ of Saskatchewan's electricity is produced by five natural gas stations, and $34 \%$ by three coal-fired power plants [3]. In 2012, these power stations released 15.7 million tonnes of $\mathrm{CO}_{2}$ into the atmosphere, accounting for about $21 \%$ of the province's total greenhouse gas emissions (Figure 1) [4]. 
Saskatchewan is Canada's leading coal producer, with annual production of about 10 million tonnes of thermal coal, or lignite. The province Saskatchewan is also Canada's leading uranium producer and accounts for more than $16 \%$ of the world's primary uranium production, second only to Kazakhstan [5].

Clean energy is environmentally friendly; that is, derived from renewable with little or no emissions. Nuclear power generation can make a significant contribution to decreasing dangerous greenhouse gas emissions.

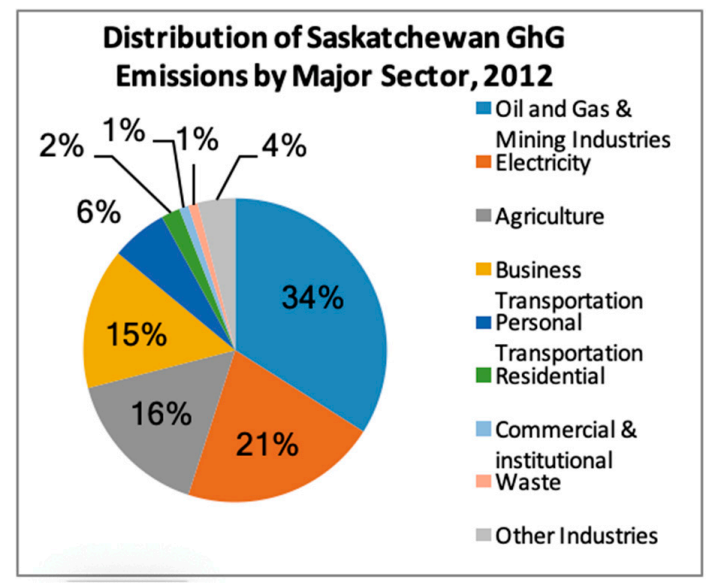

Figure 1. Distribution of Saskatchewan greenhouse gas (GHG) emissions by major sectors, 2012 [4]

The use of nuclear fission for electrical power generation was established during the 1950s. Since then, the generating capacity of reactor units has increased from 60 MWe to more than 1600 MWe [6]. Historically, nuclear power plants have been massive infrastructure projects, supplemented with significant fuel cycle operations and subsequent generation of radioactive waste. This has led to the consideration of smaller power plants. The shift towards developing smaller power plants is being driven by the higher operational costs and higher potential of accidents and greater risks associated with conventional reactors, and the increasing need to generate electricity for grid and off grid areas that require less than 4 MWe [6]. Small unit power plants can be built as individual structures or as modules to increase capacity, as required. The small unit offers flexible investment as compared to traditional reactors that are challenging to finance. Smaller units can be built below the ground, a safety improvement over the larger above-ground nuclear plants. As well, designing smaller plants in factories and shipping them to the site is more cost effective than larger plants built on-site [6].

Small modular reactors (SMRs) are capable of supplying power from different applications, such as smaller electrical grids or remote, off-grid areas. Designers point out that SMRs will be able to supply service regions where larger nuclear power plants cannot do so [7].

Alternative uses of SMRs are being considered beyond generating electricity. These include supplying steam for industrial applications and district heating systems, and producing value-added products, such as hydrogen fuel or desalinated drinking water [7].

The latest nuclear power generation technologies, which include SMRs and advanced reactors, vary significantly from traditional nuclear power plants in their size, design features, and cooling types [7]. Because SMRs have fewer risks than the big nuclear plants, they have the potential of more suitable sites. In particular, their site locations could potentially be different from past nuclear power plant projects. For example, they could be located:

- On small electrical grids where the power must remain below specified standards; for example, 300 megawatts of electricity (MWe) per each facility to sustain grid stability [7].

- At edge-of-grid or off-grid locations in the range of 2 to $30 \mathrm{MWe}$ to supply small amounts of power or where energy production is expensive and dependent on fossil fuels [7].

- In areas where old coal power plants are being retired. 
In addition, SMRs can be more cost effective, operate more safely, and have greater public acceptance. For example, since SMRs can be manufactured in different factories and then shipped to their destinations for final assembly, they can be more cost effective than traditional nuclear power plants. The smaller footprints of SMRs open up more potential suitable sites. Moreover, big nuclear power plants could be sited away from populated areas, increasing their production, maintenance, and transmission costs, whereas SMRs can be situated quite close to the places where their power is needed. SMRs offer safety improvements over larger nuclear plants. For example, some studies recommend that SMRs are built below the ground, increasing safety and security [8]. Additionally, SMRs can be sited in more earthquake-prone areas, since ground movement protection is more easily built in the SMR design.

Small modular reactors (SMRs) are the next generation of nuclear power plants. SMRs typically produce less than $300 \mathrm{MWe}$, and their basic design offers enhanced safety benefits, such as the options to reserve a smaller emergency exclusion zone and site the reactor beneath grade [9]. This flexibility gives the province the opportunity to produce its electricity through nuclear fission rather than burning fossil fuels [9].

Several studies, such as from Oak Ridge National Laboratory [10], have focused on siting SMRs for specific power generation technology applications using appropriate site-screening criteria and a geographic information system (GIS) corresponding to the environmental factors identified. Studies on siting nuclear plants have used different criteria [11], including geographical, engineering, social, and environmental criteria.

Location analysis determines how tangible assets such as land and buildings can support the performance of an activity objectively to the suppliers, clients, and other facilities to which it interfaces. According to [12], the decision process of location analysis emphasis on the systems approach to distribution is a complicated process that requires many trade-offs. The process of location analysis and selection should follow steps, which are: Identifying the dominant factors in a location, developing alternatives, and evaluating the alternatives to the site.

Several methodologies are available during location analysis, which include a load-distance model which analyzes location facility based on proximity features. The factor rating method is an analysis method that involves identifying key factors responsible for the success of the industry and giving those factors weighted value, which is then used to calculate their factor rating responsible for the success of the company. The transportation model is another technique that involves the movement of goods to different locations from where they are produced, and it is essential in finding the most efficient route for resource allocation [13]. There is also the center of gravity approach, which involves calculating the geographic coordinates to find a new facility that will minimize cost through analyzing markets and the volume of goods shipped [14].

In such a case, geographic information systems (GIS) are used, together with multi-criteria decision analysis (MCDA), which increase the efficiency and accuracy of findings during site selection [15]. In a case where several methodologies are used, this means that it is a group decision and they value the input of other members as necessary. This, hence, causes a trade-off in the group and calls for the use of multi-criteria decision analysis.

There are several techniques used in selecting location facility, especially when there is need to use geographic information systems, and hence this calls for the adoption of MCDA to get the highest accuracy of information, as well as incorporate the input of all members.

This research investigates the identification of suitable sites for SMRs across Saskatchewan, focusing on the geographical factors. This study demonstrates how geographical siting activities fit into the phases of infrastructure development and identifies the factors likely to be used to determine appropriate sites based on safety, health, environmental, and social parameters. The data used to inform the site selection process, implementation strategies for the siting process, and methods for assessing the various siting factors are determined and described. 
Saskatchewan was chosen as this study's locale because it has the unique distinction of being one of Canada's highest greenhouse gas emitters, as of 2015, due to the burning of lignite (brown coal) [16]. At the same time, it possesses the second-largest uranium reserves in the world [5].

Saskatchewan has the potential to be one of Canada's lowest greenhouse gas emitters if it switched to nuclear power generation.

The goal was to develop an objective, reproducible process for optimum SMR site selection. This study was aimed at identifying the most important spatial geographic factors in determining suitable sites for SMRs. The site suitability analysis was based on objective geographical factors. Our siting criteria did not include factors such as public perceptions, cost and cultural resource issues, energy supply and demand, disposal of radioactive waste, or SMRs' competition with other power generation technologies. Saskatchewan's governing bodies need to consider these factors.

\section{Study Area}

This study focuses on the Canadian province of Saskatchewan (Figure 2). Saskatchewan has an area of 652,330 square kilometers, with about one-eighth covered with water [17]. The southern part of the province, where population density is highest, is rolling prairie, interspersed with valleys eroded by meltwaters from the last glacial era [17]. The highest elevation is in the Cypress Hills, sitting at $1460 \mathrm{~m}$ above sea level [18]. The province has three major river systems all emptying into Hudson Bay: The North and South Saskatchewan Rivers, the Churchill River, and the Assiniboine River. The central and northern parts of the province are not heavily populated [18]. The soils around the southern part are predominantly chernozems and conducive to agriculture, while in the north, the climate and poor soil development prohibits large scale agriculture [18]. Fishing production is more notable in the north; in the south, individual farmers raise fish for their own use [18].

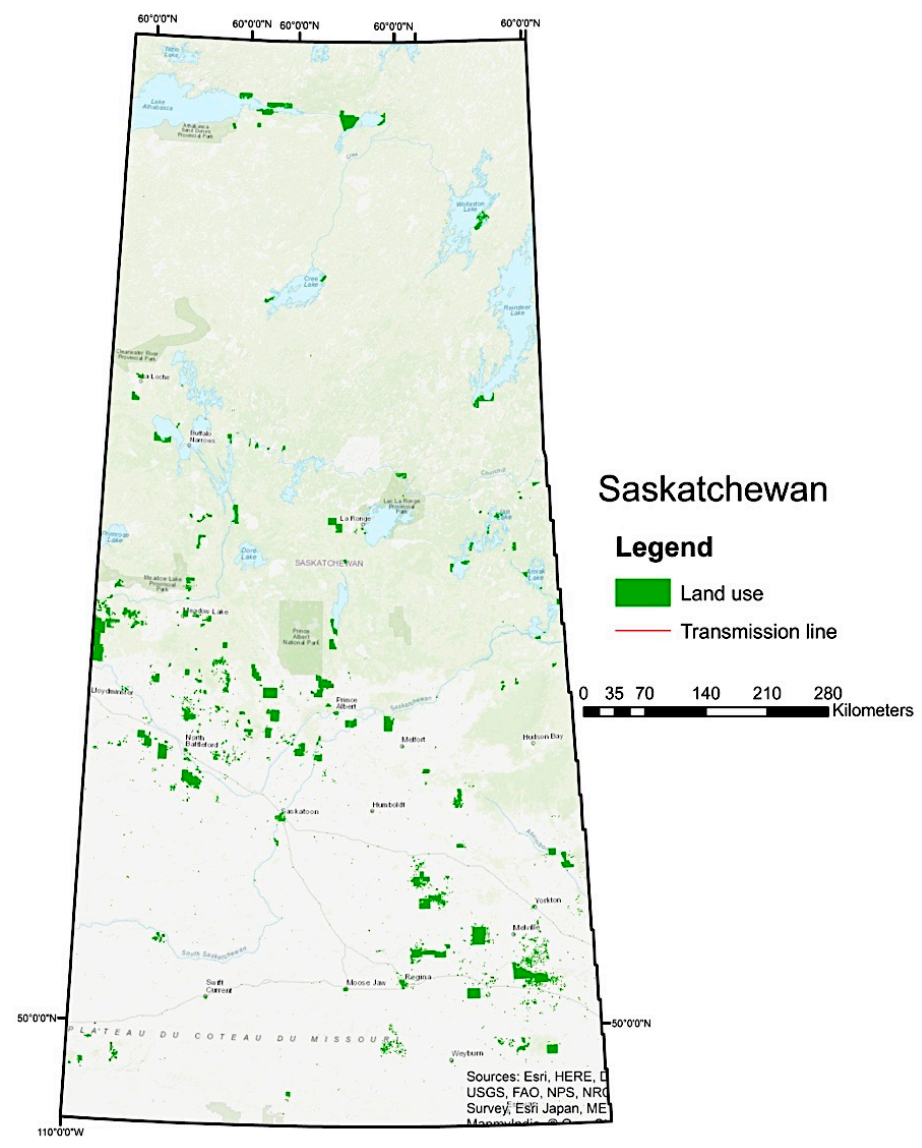

Figure 2. Small modular reactor (SMR) siting study. 


\section{Materials and Methods}

This study focused on the determination of candidate sites for SMRs in Saskatchewan. Conceptually, this process took place in four stages: (i) identifying the criteria crucial for site selection; (ii) assigning weights to the selected criteria to reflect their relative importance, (iii) evaluating the methods by which the criteria are combined in a geospatial analysis and (iv) spatial interpretation of the results, as shown in the research methods, and the research process flowchart as in the following chart (Figure 3):

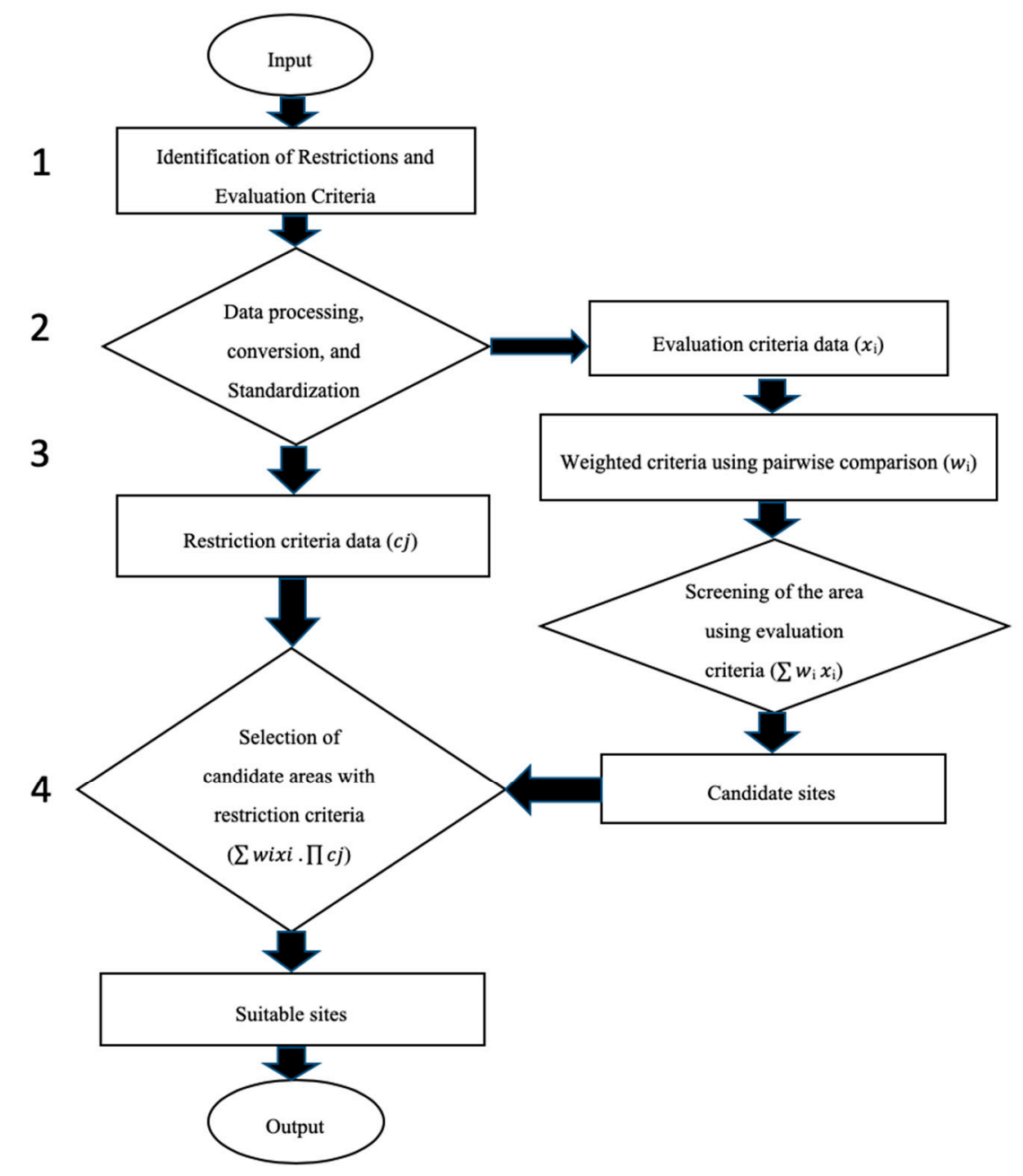

Figure 3. Study flowchart.

\subsection{Identifying Site Selection Criteria and Data}

Potential siting criteria for SMRs were identified from various sources, most stemming from publications of the Canadian Nuclear Safety Commission (CNSC): License to Construct a Nuclear Power Plant [19], Site Evaluation for New Nuclear Power Plants [20], Design of New Nuclear Power Plants [21], and Small Modular Reactors: Regulatory Strategy, Approaches and Challenges [7].

Criteria for siting included population distribution and density, surface water, land use, protected land, airports, earthquakes and surface-faulting hazards, electricity infrastructure, existing power plants, flooding, wetlands, transportation, groundwater, agricultural areas, and slope. Other criteria were not used in this study as they were not specific to SMRs or were not applicable to the Saskatchewan environment (e.g., earthquakes, mines, existing power plants, fishery areas, forest fires, volcanoes, and tornadoes). Although important, these factors have more impact on the construction of a reactor at a particular site than the selection of that site. For example, Saskatchewan has no volcanoes. 


\subsubsection{Identification of Restrictions and Evaluation Criteria}

The selected criteria were refined by determining which identified site restrictions and which were more useful for inter-site comparison evaluations. Site restriction criteria limited (excluded) possible alternatives based on Boolean relations (true/false). The evaluation criteria could then be quantified according to the degree of suitability for all feasible alternatives [22]. Determining the differences between the criteria was adopted according to the study goals and the CNSC [7,19-21] regulations.

After reviewing the CNSC [7,19-21] environmental and public safety regulations, nine restriction criteria and five evaluation criteria were adopted to find the suitable sites for SMRs. These were selected because of their relevance to smaller reactors and their applicability in the Saskatchewan environment. These restriction and evaluation criteria are shown in Tables 1 and 2.

Table 1. Restriction criteria for SMR site selection in Saskatchewan [7,19-21].

\begin{tabular}{ll}
\hline Restriction Criteria & Description \\
\hline Protected areas & $\begin{array}{l}\text { Includes wildlife species, wildlife habitats and unique or ecologically sensitive areas, } \\
\text { national parks, Canada terrestrial, and water protected areas. }\end{array}$ \\
\hline Land uses & $\begin{array}{l}\text { The featured entities are: Dam, liquid storage facility, tank, building, landmark feature, } \\
\text { chimney, cell tower, waste, leisure area, residential area, commercial, and institutional area, } \\
\text { and ritual cultural area. }\end{array}$ \\
\hline Flooding areas & $\begin{array}{l}\text { Site assessment must consider surface water hydrology and instrumentally recorded } \\
\text { hydrological data, such as water levels and flow rates. Lands that have flood potential. }\end{array}$ \\
\hline Airports & Airport and land near airports. \\
\hline Population density & $\begin{array}{l}\text { Land with a population density greater than } 200 \text { people per square km (500 persons per } \\
\text { square mile) is excluded [23]. }\end{array}$ \\
\hline Wetlands & Wetland areas that are covered by water and have an organic matter. \\
\hline Groundwater & $\begin{array}{l}\text { Groundwater is taken into consideration through hydrogeological investigation based on } \\
\text { data modeling. The impacts of siting SMRs on groundwater flow systems and } \\
\text { contamination require assessment. Deeper groundwater seems to be preferable, as water } \\
\text { reduces the strength of soil materials. }\end{array}$ \\
\hline Agriculture & $\begin{array}{l}\text { These lands are evaluated based on their public nature. Agriculture is classified into } \\
\text { different classes based on ISO 19131 Canada Land Inventory (CLI). All agricultural lands } \\
\text { and lands suitable for agriculture must be evaluated. }\end{array}$ \\
\hline Slope & \begin{tabular}{l} 
Lands with greater than $15 \%\left(~ 8^{\circ}\right)$ slope are excluded for the Normal case [24]. \\
\hline
\end{tabular}
\end{tabular}

Table 2. Evaluation criteria for SMR site selection in Saskatchewan [7,19-21].

\begin{tabular}{ll}
\hline Evaluation Criteria & Description \\
\hline Populated areas & $\begin{array}{l}\text { SMRs need to be located relatively close to major population or customer bases. Placing them in } \\
\text { very close proximity to populations is avoided, predominately as a safety measure. Highly } \\
\text { populated areas will not be considered. Thus, populated areas must be evaluated. }\end{array}$ \\
\hline Railways & $\begin{array}{l}\text { One of the advantages of an SMR is the ability to manufacture and then ship it to the site. } \\
\text { Therefore, railways are required for siting SMRs, as rail transport is the key means of equipment } \\
\text { transport. }\end{array}$ \\
\hline \multirow{2}{*}{ Transmission linse } & $\begin{array}{l}\text { Practical and strategic connections to the transmission grid to supply electricity to areas of } \\
\text { demand. The ability of the grid system to accept power in-feed at a site location, without } \\
\text { requiring costly and time-consuming reinforcement, is critical. Due to high capital and low } \\
\text { running costs, nuclear reactors should be sited to work as a base load plant; the network } \\
\text { infrastructure should enable continuous operation at full power [25]. Also, remote locations } \\
\text { off-grid are considered in this study. Thus, the transmission line criterion must be evaluated } \\
\text { based on the distance of how an SMR needs to be close to a transmission line. }\end{array}$ \\
\hline Roads & $\begin{array}{l}\text { SMRs can be manufactured and then ship it to the site. So, roads to transport SMR equipment } \\
\text { and to afford site access are required for siting SMRs. }\end{array}$ \\
\hline Surface water & $\begin{array}{l}\text { Surface water refers to the major water source-lakes and rivers-found in a specific area. } \\
\text { Surface water must be determined to avoid any potential impact of the reactor's operation, and } \\
\text { contaminant potential also must be determined to be considered in SMR operations and cooling. }\end{array}$ \\
\hline
\end{tabular}




\subsubsection{Data Finding, Processing, and Conversion}

After the criteria were determined, matching datasets were found. Various agencies have created geospatial datasets for specific purposes, so some could not be directly combined. Thus, various data formatting processes and conversions were implemented in preparation for weighting and combining data, such as scaling, resolution adjustment, coordinate system reprojection, map extent selection, queries, buffering, and transformation of data from vectors into raster data structures.

Data for the entire province for some criteria were not found. For example, agricultural data were available only for southern Saskatchewan because climatic (a short growing season) and petrologic (a lack of rock) conditions in the north restrict agriculture. Northern Saskatchewan was classified in this research as unsuitable for agriculture. In addition, groundwater data were unavailable for northern Saskatchewan, which is dominated by igneous and metamorphic rocks of Precambrian origin. [26,27] reported that in Manitoba's Lac du Bonnet Batholith, groundwater movement down to about $200 \mathrm{~m}$ is expected. Saskatchewan's groundwater flow in the Canadian Shield rocks is likely similar to that in other locations in the Canadian Shield [26]. Groundwater in the Canadian Shield is both scarce and very deep. Thus, deeper groundwater seems to be preferable, as water reduces the strength of soil materials.

\subsection{Data Standardization}

The data were measured on various enumeration scales and needed to be standardized before being combined or changed. Common standardization scales included 0.0-1.0 real number scales and 0-255 integer scales [28]. Such scales could be used to develop fuzzy set membership functions [28]. The map layer data were converted into a range of 1-5 to measure the suitable areas for each map layer. In this case, the highest value was allocated to the very suitable areas, and the lowest value to the unsuitable areas. Table 3 describes the standardization values used.

Table 3. Standardization scale of suitability classes.

\begin{tabular}{cc}
\hline Value & Description \\
\hline 1 & Unsuitable \\
2 & Less suitable \\
3 & Moderately suitable \\
4 & Suitable \\
5 & Very suitable \\
\hline
\end{tabular}

The ranges in each criterion are used for demonstration purposes, in Tables 4-6 as example. They represented reasonable estimates of the importance of each criterion based on the observed ranges in the data and shared knowledge from the project team. It was acknowledged that they could benefit from additional fine-tuning with input from domain experts. However, such expert knowledge would also be somewhat subjective, and experts could have provided different recommendations.

As shown in Figure 4, the geographic distances for the siting criteria exclusion zones used in this study were standardized into three fuzzy cases:

- Open;

- Normal;

- Restrictive.

The spatial distance between a reactor location and its various restrictions and evaluation criteria features are important geographical measurements for SMR siting. Currently, no legislative or regulatory requirements for sizing the distance between SMRs and siting criteria exist, nor do restrictions on minimum distances between SMRs and siting criteria. Consequently, the geographical measurements, or the standardization values for the siting criteria, are fuzzy and may vary between 
government bodies and vendors. The variations stem from the stakeholders' perspectives and knowledge of the interaction between siting SMRs with the other siting criteria.

To better understand the effects of such variations, SMR siting studies should focus on different cases. In this study, the Open case, in which the reactor was placed near the siting criteria, could be contrasted to the Restrictive case, which placed more distance between the SMR and the siting criteria. For example, the Open case set $2 \mathrm{~km}$ as the spatial distance between the SMR and the land use criterion, whereas in the Restrictive case, a spatial distance of $10 \mathrm{~km}$ was preferred. Drawing from previous examples, different cases, including the Normal case between the Open and Restrictive cases, were produced (Figure 4). Measurements for demonstration purposes were included to address the vested interests of government parties and vendors.

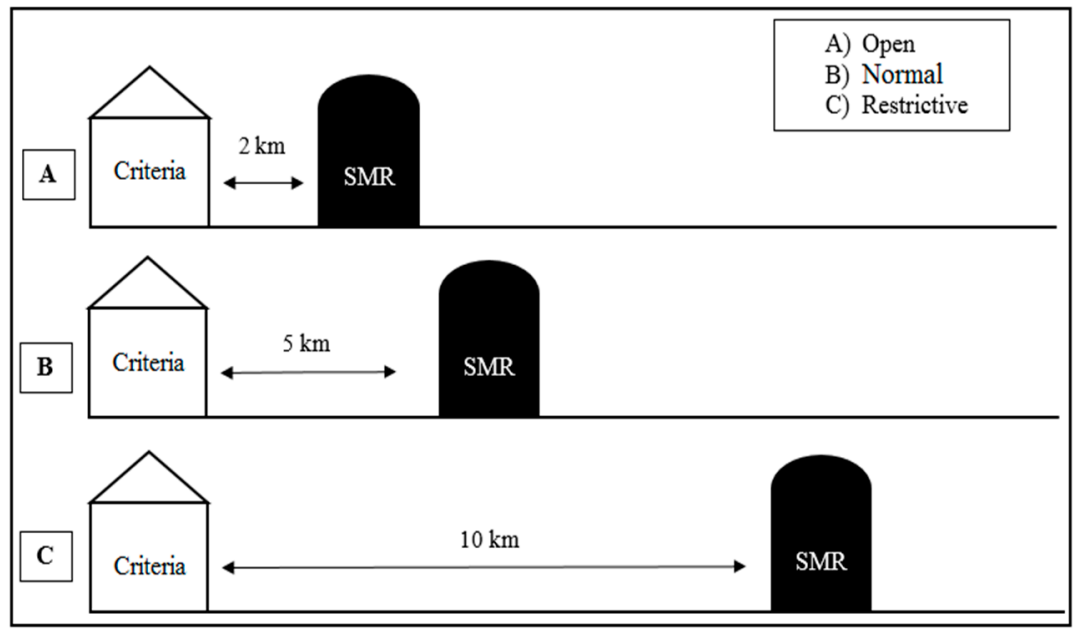

Figure 4. Comparison of siting cases for SMRs.

Fuzzy standardization is many of logical values in which the truth values of variables may be between 0 and 1. It was applied to the evaluation criteria layers, as shown in Table 4, for the Open case and the Normal and Restrictive cases will show them in the final maps. The ranges used in each category were used for demonstration purposes. They represent reasonable estimates of the importance of each criterion based on observed ranges in the data and shared knowledge. It is acknowledged, however, that they may benefit from additional fine-tuning with input from domain experts. Even so, such expert knowledge is somewhat subjective and different experts may provide different recommendations.

Table 4. Restriction criteria standardization values.

\begin{tabular}{cccc}
\hline \multirow{2}{*}{ Restriction Criteria } & \multicolumn{3}{c}{ Exclusion Zone } \\
\cline { 2 - 4 } & Open & Normal & Restrictive \\
\hline Protected areas & $<3 \mathrm{~km}$ & $<5 \mathrm{~km}$ & $<10 \mathrm{~km}$ \\
Land uses & $<2 \mathrm{~km}$ & $<5 \mathrm{~km}$ & $<10 \mathrm{~km}$ \\
Flooding areas & $<1 \mathrm{~km}$ & $<2 \mathrm{~km}$ & $<5 \mathrm{~km}$ \\
Airports & $<2 \mathrm{~km}$ & $<7 \mathrm{~km}$ & $<10 \mathrm{~km}$ \\
Population density & $<3 \mathrm{~km}$ & $<5 \mathrm{~km}$ & $<8 \mathrm{~km}$ \\
Wetlands & Excluded & Excluded & Excluded \\
Groundwater & Evaluated & Evaluated & Evaluated \\
Agriculture & Evaluated & Evaluated & Evaluated \\
Slope & $<25 \%$ & $<15 \%$ & $<10 \mathrm{~km}$ \\
\hline
\end{tabular}


Table 5. Evaluation criteria standardization values for the Open case.

\begin{tabular}{cccccc}
\hline \multicolumn{5}{c}{ Degree of Importance } \\
\hline \multirow{2}{*}{ Evaluation Criteria } & $\mathbf{1}$ & $\mathbf{2}$ & $\mathbf{3}$ & $\mathbf{4}$ & $\mathbf{5}$ \\
\cline { 2 - 6 } & Unsuitable & Less Suitable & Moderately Suitable & Suitable & Very Suitable \\
\hline Populated areas & $>20 \mathrm{~km}$ & $15-20 \mathrm{~km}$ & $10-15 \mathrm{~km}$ & $5-10 \mathrm{~km}$ & $1-5 \mathrm{~km}$ \\
Surface water & $>20 \mathrm{~km}$ & $15-20 \mathrm{~km}$ & $10-15 \mathrm{~km}$ & $5-10 \mathrm{~km}$ & $0-5 \mathrm{~km}$ \\
Railways & $>20 \mathrm{~km}$ & $15-20 \mathrm{~km}$ & $10-15 \mathrm{~km}$ & $5-10 \mathrm{~km}$ & $0-5 \mathrm{~km}$ \\
Roads & $>20 \mathrm{~km}$ & $15-20 \mathrm{~km}$ & $10-15 \mathrm{~km}$ & $5-10 \mathrm{~km}$ & $0-5 \mathrm{~km}$ \\
Transmission lines & $>20 \mathrm{~km}$ & $15-20 \mathrm{~km}$ & $10-15 \mathrm{~km}$ & $5-10 \mathrm{~km}$ & $0-5 \mathrm{~km}$ \\
\hline
\end{tabular}

Most of the restriction criteria were standardized on a binary scale: Either an SMR is permitted in this location or it is totally excluded. For example, airports, protected areas, wetlands, and areas of steep slopes were completely removed from the siting analysis. Fuzzy standardization scales were used for depth to groundwater and agricultural land use classes (Table 6).

Table 6. Agriculture and groundwater standardization table for the Open case.

\begin{tabular}{cccccc}
\hline \multicolumn{5}{c}{ Degree of Importance } \\
\hline Restriction & $\mathbf{1}$ & $\mathbf{2}$ & $\mathbf{3}$ & $\mathbf{4}$ & $\mathbf{5}$ \\
\cline { 2 - 6 } Criteria & Unsuitable & Less Suitable & Moderately Suitable & Suitable & Very Suitable \\
\hline Groundwater & $0-1 \mathrm{~m}$ & $1-4 \mathrm{~m}$ & $4-7 \mathrm{~m}$ & $7-10 \mathrm{~m}$ & $>10 \mathrm{~m}$ \\
Agriculture & 1 & 1 & 2 & 3 & $4-10$ \\
\hline
\end{tabular}

In addition to standardizing the values among the data layers, a common spatial base for the analysis was required. The selection of an appropriate minimum mapping unit (MMU) was based on the resolution and precision of the source data and the level of detail required in the analysis. When selecting an appropriate MMU, it is difficult to balance precision and computational efficiency. As the MMU became smaller, the analysis became more precise at the expense of an exponential increase in data storage and processing requirements. The MMU had to be large enough to situate an SMR but not so large so that small but viable locations were missed. It was decided that 4 hectares $(200 \mathrm{~m} \times 200 \mathrm{~m})$ was an appropriate MMU, as it was the smallest parcel of land on which an SMR could be located.

\subsection{Assigning Weights to the Selected Criteria}

Weights and scores are typically assigned based on researchers' knowledge of the study area and in consultation with local experts and decision makers [11]. Generally, higher weightings are typically given to the principal factors that have a potentially stronger impact-for example, distance from urban areas. The assigning of weights to selected criteria was done through different steps, as follows.

\subsubsection{Analytic Hierarchy Process Method}

Saaty (2008) [29] developed a decision-making process called the analytical hierarchy process (AHP) method, which has been shown to have wide application for determining preferences based on a wide range of tangible and intangible criteria [30]. The AHP method begins by establishing the priority of criteria using pair-wise criteria weights, as shown in the following section.

\subsubsection{Pair-Wise Comparison Method}

Pairs of criteria were compared, and their relative importance was rated. Saaty (2008) [29] used a 9-point rating scale in comparisons (Table 7). Once the criteria were compared, local priorities for criteria were obtained, and the consistency ratio of the judgments was determined in the following. 
Table 7. Pair-wise comparison rating scale [29].

\begin{tabular}{cc}
\hline Numerical Ratings & Verbal Judgments \\
\hline 1 & Equally important \\
3 & Moderately more important \\
5 & Strongly more important \\
7 & Very strongly more important \\
9 & Extremely more important \\
\hline
\end{tabular}

A weighted sum vector $\{W s\}$ was calculated by multiplying the weight vector $\{W\}$ for the first criterion by the first column of the original pair-wise comparison matrix $[C]$, then multiplying the second weight times the second column, the third criterion times the third column, and so on.

$$
\{W s\}=[C] \cdot\{W\}
$$

Equations (2)-(4) show how the consistency ratio was calculated to determine whether the comparison matrix was acceptable. The consistency vector was determined by dividing the weighted sum vector by the criterion weights established previously:

$$
\{\text { consis }\}=\{W s\} \cdot\{1 / W\}
$$

The consistency index was calculated as:

$$
C I=\frac{\lambda-\mathrm{n}}{n-1}
$$

where $\lambda$ is the average value of the consistency vector and $n$ is the number of criteria.

The consistency ratio (CR) was defined as:

$$
C R=\frac{C I}{R I}
$$

where random consistency index $(R I)$ was the $\mathrm{n}^{*} \mathrm{n}$ matrix if the pairwise comparisons were completely random, as given in Table 8 .

Table 8. Consistency index for randomly generated matrices [28].

\begin{tabular}{ccccccccccc}
\hline Size & $\mathbf{1}$ & $\mathbf{2}$ & $\mathbf{3}$ & $\mathbf{4}$ & $\mathbf{5}$ & $\mathbf{6}$ & $\mathbf{7}$ & $\mathbf{8}$ & $\mathbf{9}$ & $\mathbf{1 0}$ \\
\hline RI & 0.00 & 0.00 & 0.58 & 0.90 & 1.12 & 1.24 & 1.32 & 1.41 & 1.45 & 1.49 \\
\hline
\end{tabular}

A CR of less than $10 \%$ indicates that a matrix has acceptable consistency [31]. In this study, two sets of criteria weights were generated, with consistency ratios of $5.4 \%$ and $1.7 \%$ (Table 9).

\subsection{Geospatial Analysis}

Once a set of criteria is selected, and relative weights defined, the final step in the analysis is to combine them with the intent of producing a map identifying the locations of candidate sites. Multi-criteria decision analysis (MCDA) is commonly used in GIS with binary overlays and the weighted linear combination (WLC), as detailed in the following sections. Two important methods of MCDA commonly used in GIS are binary raster overlay and weighted linear combination. These are detailed below. 
Table 9. Sample criteria weights and rankings.

\begin{tabular}{|c|c|c|c|c|c|c|c|c|c|c|c|}
\hline \multicolumn{6}{|c|}{ First Evaluation Criteria Weights } & \multicolumn{6}{|c|}{ Second Evaluation Criteria Weights } \\
\hline \multicolumn{6}{|c|}{ Pairwise Comparison Matrix } & \multicolumn{6}{|c|}{ Pairwise Comparison Matrix } \\
\hline & $\begin{array}{c}\text { Transmission } \\
\text { Line }\end{array}$ & Railways & Highways & $\begin{array}{l}\text { Populated } \\
\text { areas }\end{array}$ & $\begin{array}{c}\text { Surface } \\
\text { water }\end{array}$ & & $\begin{array}{c}\text { Transmission } \\
\text { line }\end{array}$ & Railways & Highways & $\begin{array}{l}\text { Populated } \\
\text { areas }\end{array}$ & $\begin{array}{c}\text { Surface } \\
\text { water }\end{array}$ \\
\hline $\begin{array}{c}\text { Transmission } \\
\text { lines }\end{array}$ & 1.0 & 2.0 & 1.0 & 0.5 & 1.0 & $\begin{array}{c}\text { Transmission } \\
\text { lines }\end{array}$ & 1.0 & 1.0 & 0.5 & 0.5 & 1.0 \\
\hline Railways & 0.5 & 1.0 & 1.0 & 1.0 & 1.0 & Railways & 1.0 & 1.0 & 1.0 & 1.0 & 1.0 \\
\hline Highways & 1.0 & 1.0 & 1.0 & 0.3 & 1.0 & Highways & 2.0 & 1.0 & 1.0 & 1.0 & 1.0 \\
\hline $\begin{array}{c}\text { Populated } \\
\text { areas }\end{array}$ & 2.0 & 1.0 & 3.0 & 1.0 & 1.0 & $\begin{array}{c}\text { Populated } \\
\text { areas }\end{array}$ & 2.0 & 1.0 & 1.0 & 1.0 & 1.0 \\
\hline Surface water & 1.0 & 1.0 & 1.0 & 1.0 & 1.0 & Surface water & 1.0 & 1.0 & 1.0 & 1.0 & 1.0 \\
\hline \multicolumn{6}{|c|}{ Weight Priority and Ranking } & \multicolumn{6}{|c|}{ Weight Priority and Ranking } \\
\hline Category & Criteria & Priority & \multicolumn{3}{|c|}{ Rank } & Category & Criteria & Priority & \multicolumn{3}{|c|}{ Rank } \\
\hline 1 & $\begin{array}{c}\text { Transmission } \\
\text { lines }\end{array}$ & $19.60 \%$ & \multicolumn{3}{|c|}{2} & 1 & $\begin{array}{c}\text { Transmission } \\
\text { lines }\end{array}$ & $15.2 \%$ & \multicolumn{3}{|c|}{5} \\
\hline 2 & Railways & $17.20 \%$ & \multicolumn{3}{|c|}{4} & 2 & Railways & $19.7 \%$ & \multicolumn{3}{|c|}{3} \\
\hline 3 & Highways & $15.40 \%$ & \multicolumn{3}{|c|}{5} & 3 & Highways & $22.7 \%$ & \multicolumn{3}{|c|}{2} \\
\hline 4 & Population & $28.70 \%$ & \multicolumn{3}{|c|}{1} & 4 & Population & $22.7 \%$ & \multicolumn{3}{|c|}{1} \\
\hline 5 & Surface water & $19.10 \%$ & \multicolumn{3}{|c|}{3} & 5 & Surface water & $19.7 \%$ & \multicolumn{3}{|c|}{4} \\
\hline
\end{tabular}




\subsubsection{Raster Overlay Methods}

A raster overlay is a common GIS operation that merges multiple data layers to determine the relationships. Overlay methods create a composite map from multiple data layers by combining their geometry and attributes.

\subsubsection{Weighted Linear Combination}

WLC is a combination MCDA method that incorporates the relative importance of criteria. The WLC technique consolidates factors by applying a weight to every element to yield a suitability map. The determination of suitable siting alternatives is done by multiplying the average weight by the criteria scores and then by the product of restriction criteria, such as:

$$
S=\sum_{i=1}^{n} W i X i \cdot \prod c j
$$

where $S$ is suitability, $W i$ is the weight of factor $i, X i$ is the criterion score of factor $i$, and $\prod c j$ is a product operation.

\section{Results}

\subsection{Evaluation and Restriction Criteria Maps}

Figures 5 and 6 show only the individual site criteria map layers for the Open case of siting SMRs, based on the evaluation criteria recommended at the end of this study. The other cases are only included in the final results for more information and to be discussed.

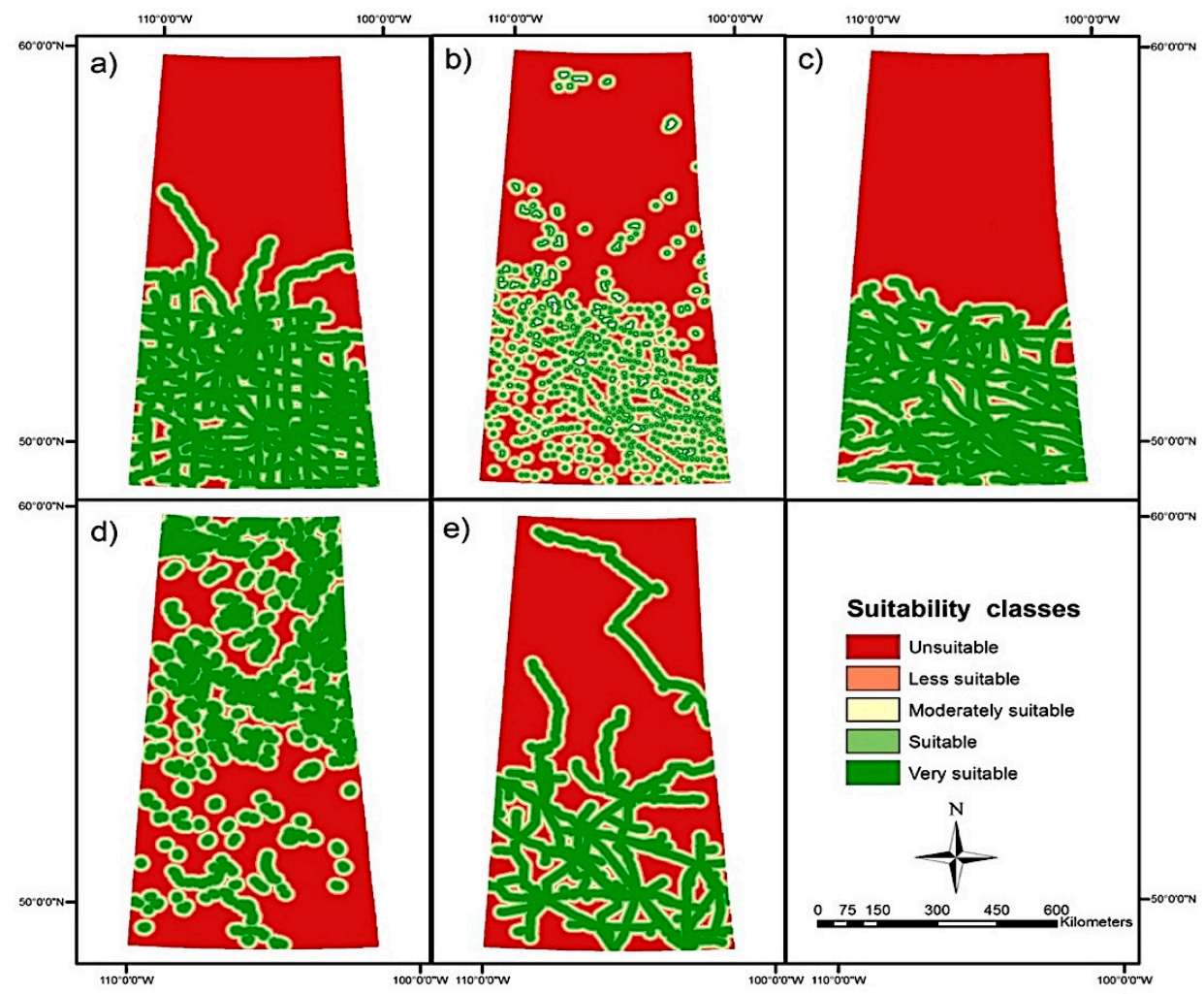

Figure 5. Evaluation criteria maps: (a) Highways, (b) populated areas, (c) railways, (d) surface water, and (e) transmission lines. 


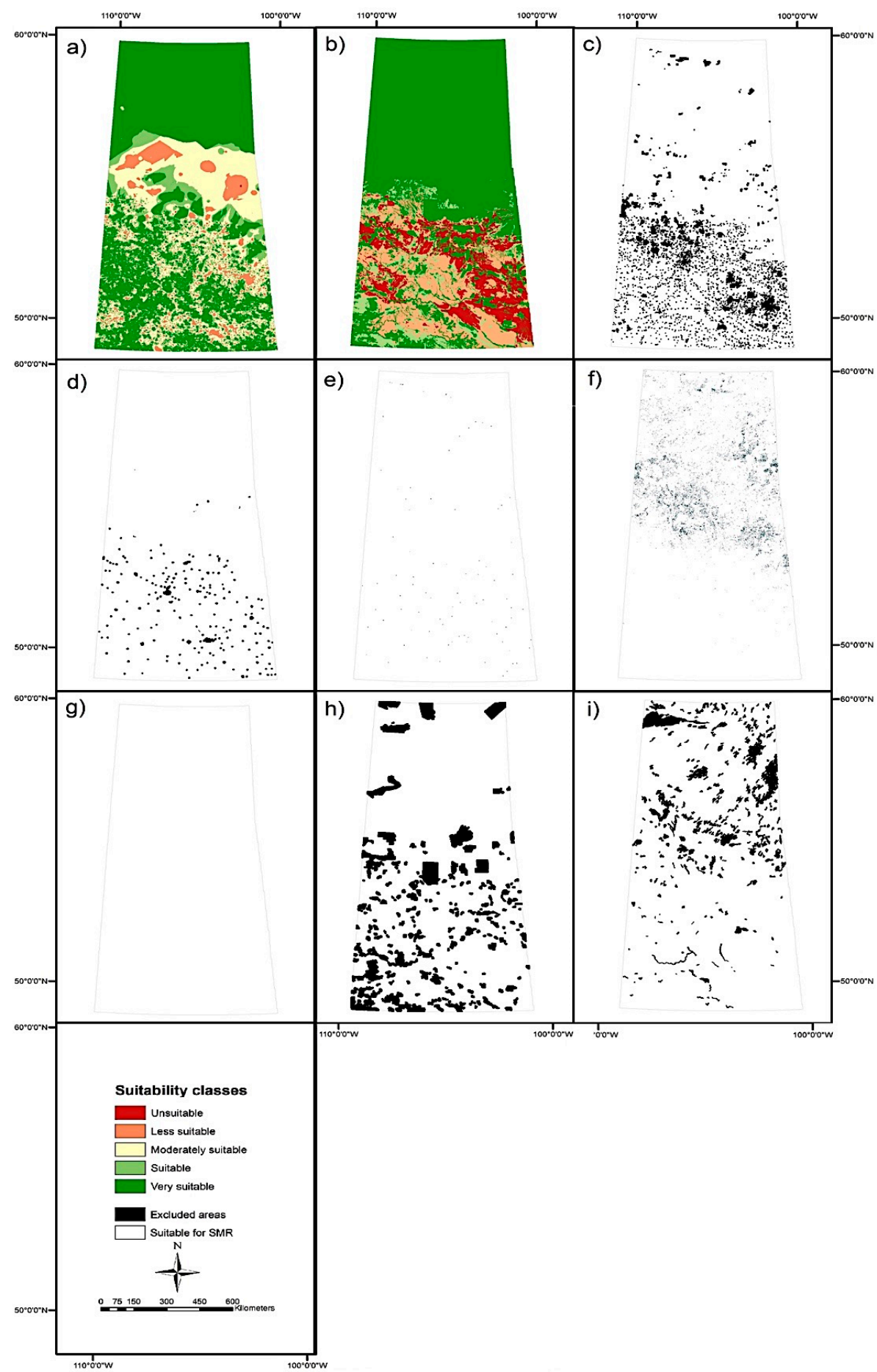

Figure 6. Restriction criteria maps: (a) Groundwater, (b) agriculture, (c) land use, (d) population density, (e) airports, (f) wetlands, (g) slope, (h) protected areas, and (i) flooding areas.

\subsection{SMR Siting Suitability Maps}

All the suitability and exclusion criteria were combined using the GIS-MCDA methods to produce SMR siting suitability maps. In Figure 7, sections (a) and (b) show the SMR siting suitability for the Open case with the first and second sets of evaluation criteria weights. In Figure 7, sections (c) and (d) show the SMR siting suitability for the Normal case with the first and second sets of evaluation criteria weights. In Figure 7, sections (e) and (f) show the SMR siting suitability for the Restrictive case with the first and second sets of evaluation criteria weights. 


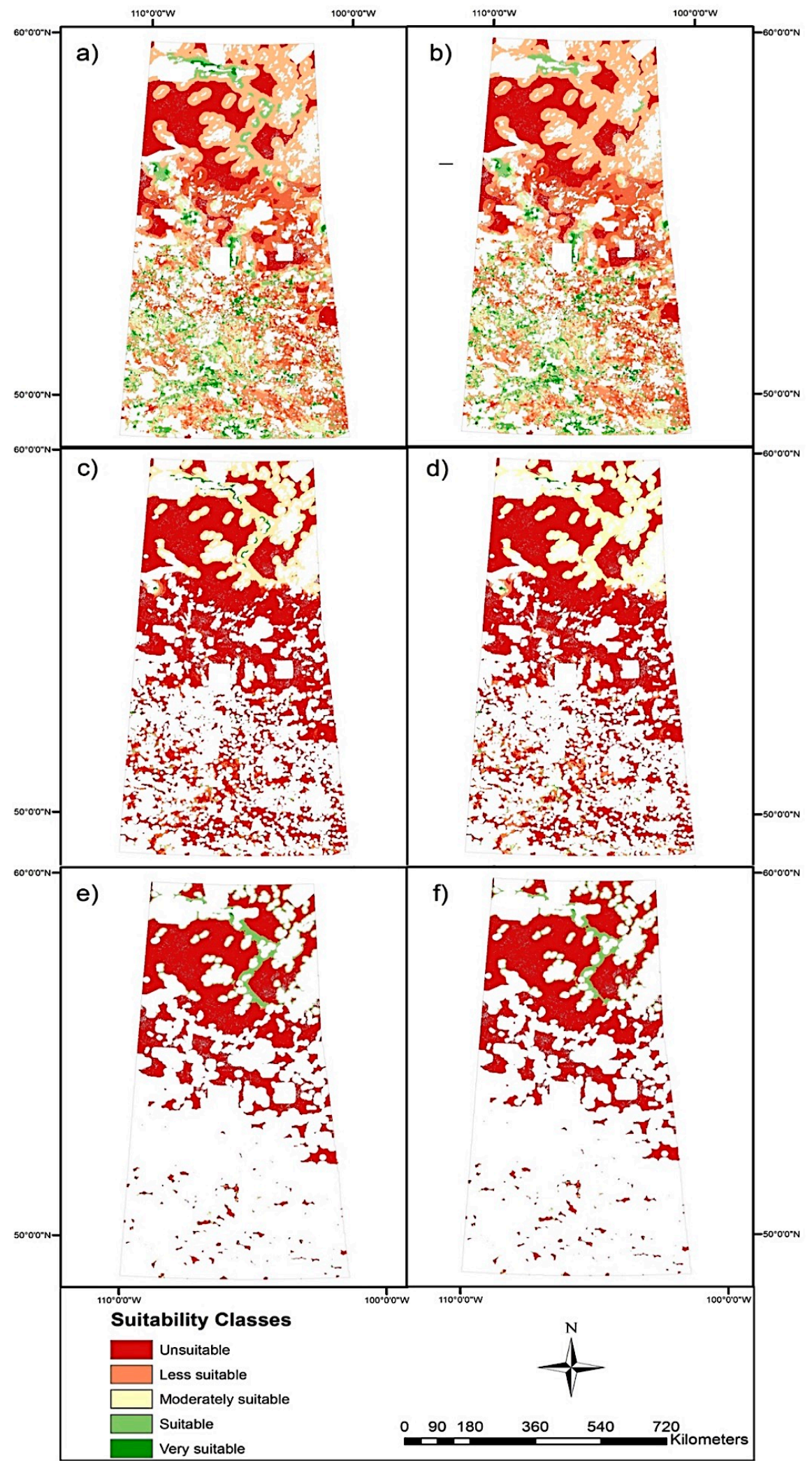

Figure 7. Open, Normal, and Restrictive cases final maps with the two-different set of weights: (a) Open case final map with the first set of weights; (b) Open case final map with the second set of weights; (c) Normal case final map with the first set of weights; (d) Normal case final map with the second set of weights; (e) Restrictive case final map with the first set of weights; and (f) Restrictive case final map with the second set of weights. 
The following chart (Figure 8) compares the total areas of the very suitable areas class in the final maps for the three cases. The Open case offers more potential for suitable areas than do the other cases, due to the geographical distances considered for both the evaluation criteria and restriction criteria. The Restrictive case offers less very suitable areas than the other cases, due to the high geographical distance considered for all the criteria. Based on Figures 7 and 8, the Open case features several suitable areas, as compared to the other cases. Notable suitable characteristics include meeting the SMR safety benefits criteria and the evaluation criteria of accessibility to utilities, such as surface water, transmission lines, highways, railways, and populated areas. These positive attributes offer significant SMR siting opportunities.

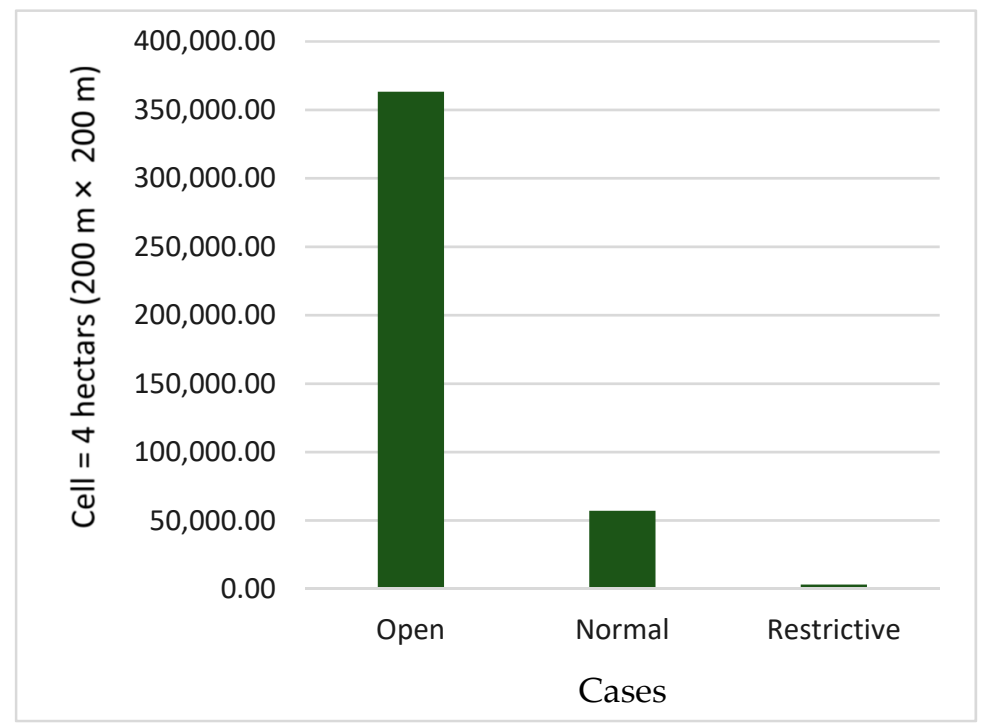

Figure 8. A comparison of total hectares of the very suitable class in the final maps for the three cases.

\section{Discussion}

The Open case (Figure 7a,b) has many suitable areas due to the small geographic distances for the restriction criteria exclusion zones. The Restrictive case (Figure 7e,f) has no suitable areas due to the large geographic distances for the restriction criteria exclusion zones. The Normal case (Figure 7c,d), which falls between the other cases, has fewer suitable areas and many unsuitable areas compared to the Open case.

The criteria evaluation weights in the final results (e.g., Figure 7a,b) have less effect between the two figures (e.g., Figure 7c,d) due to the small variation in the evaluation criteria weights (Table 9). A significant increase in the variation between weights, therefore, will be reflected in a similar, significant increase in changes in the maps. Comparing the evaluation criteria weights and the study cases reveals that the evaluation criteria weights have minimal impact on the study areas, whereas the study cases have the greatest impact.

Establishing appropriate criteria is a crucial step in any site selection study. The criteria considered in this study were for SMRs that produce 25-300 MWe of energy. SMRs have different criteria and safety requirements than traditional reactors. For example, a traditional reactor needs access to a large source of cooling water, but SMRs have greatly reduced water needs. The final map in (Figure 7a,b) shows several suitable areas that are not close to major water sources but can be considered as acceptable because some SMRs under development do not use any water for cooling. Considering the important geographical criteria that fit the study area, therefore, is a crucial component of the research.

The siting analyses criteria for Figure 7 are based on criteria defined by various Canadian federal regulation documents. All the criteria established in these studies need to be considered; however, some criteria are specific to a given country's location, geography, environment, and strategic policies. Essentially, different places lead to different site analyses. For example, the slope criterion is a negligible 
factor in Saskatchewan, as shown in Figure $6 \mathrm{~g}$ for the Open case, but was a significant criterion in a study in the United States, where approximately $40 \%$ of the land was excluded due to excessive slope [32]. Another example considers how a reactor's cooling water requirements could lead to very different siting scenarios if it were built in Saudi Arabia or Saskatchewan. Saudi locations would be restricted to coastal regions, but in Saskatchewan, water, as shown in Figure $5 d$, is available from lakes and rivers widely distributed across the province. The restriction criteria considered in this study are important for siting SMRs based on the geography of the study area. The criteria not considered in this study remain important for siting SMRs in different geographical locations, as discussed in the "Identifying Site Selection Criteria and Data" Section 2.1.

The evaluation criteria used in this study were chosen based on providing a high level of discrimination and readily accessible data for nominal SMR power plants operating at less than 300 MWe. Regardless of the SMR design, the reactor core and plant infrastructure require access to railways for delivering the reactor core and waste transportation and roads for workers, construction, and emergency response. The plants need a water supply for operation. Transmission lines are essential to deliver electricity to customers. Other evaluation criteria not considered but of importance are uranium mining and retired power plant locations. These, too, are addressed in the "Identifying Site Selection Criteria and Data" section (Section 2.1).

SMRs pose lower risk than larger nuclear power plants, so they can be built relatively close to consumers to minimize the cost of service transmission (e.g., power and heat). Safety improvements also include a smaller emergency planning zone (EPZ). SMRs, thus, can be relatively close to population areas and still minimize the potential consequences of accidents [33]. As shown in Figure 7a,b for the Open case and in the populated areas criterion map Figure $5 \mathrm{~b}$, a 1-km protected zone around populated areas was considered in the Open case with a small geographical distance. A sizable protected zone was considered in the Restrictive case. In Figure 7e,f, with the populated areas criterion map for the Restrictive case, suitable SMR sites are relatively far from population areas, at a distance of $5 \mathrm{~km}$. Considering $5 \mathrm{~km}$ in the Restrictive case results in losing many suitable areas, as seen in comparing Figure $7 \mathrm{e}, \mathrm{f}$ with Figure $7 \mathrm{a}, \mathrm{b}$.

The Reference [7], p. 16, stated that "there are no legislative or regulatory requirements for EPZ sizing in Canada and therefore no restrictions currently in place on minimum EPZ size." The location of an SMR, however, still needs to "mitigate the radiological consequences of potential releases of radioactive materials that may result from accident conditions" [7], p. 14. [32] reported that the recommended EPZ for SMRs in the Unites States is 1-5 miles $(1.6-8 \mathrm{~km})$. The appropriate EPZ for SMR design is still debated by many researchers and regulators. Technology developers are seeking ways to reduce EPZ size by using technology improvements [7]. Reducing the protected area around populated areas creates more potential suitable sites.

Some criteria considered to be important for siting SMRs are not expected to vary much over time. Such static criteria include slope and groundwater. Other criteria are more dynamic; for instance, population density, flooding areas, and surface water. In this study, more attention was paid to the dynamic criteria because they change with the time. For instance, in the Open case, a 3-km zone was applied to highly populated areas (Figure $5 \mathrm{~b}$ ), and a 1-km buffer zone was placed around potential flood areas (Figure 6i).

Surface water refers to the major water sources in a specific area, including lakes and rivers. Siting SMRs close to water sources is vital for cooling many reactors. If a water source is far from a suitable site, as considered in some areas in the Open case's surface water criterion map (Figure 5d), different SMR technologies for cooling the reactor can be used. These technologies offer the benefits of reducing water use and plant acreage and expanding potential siting options.

Ecological and environmental aspects in the event of accidents or radioactive release need to be considered if a reactor plant is placed near important places. The distance between the reactor plant and the restriction criteria is a key consideration. For example, a $3-\mathrm{km}$ protected area was the smallest exclusion geographical distance considered in the Open case (Table 4). The improved design 
of present-day SMRs, with enhanced safety benefits and operations, means that sites can be relatively close to consumer locations to ensure the supply of both electricity and heat.

Water sources are a second ecological and environmental consideration. Typically, electric plants are near rivers, lakes, or other water bodies to supply the reactor with cooling water. Hot effluents from the reactor, which increase the water temperature and thereby pose serious risks to the ecology and aquatic populations, need to be minimized. The surface water criterion map (Figure $5 \mathrm{~d}$ ) considers major surface water sources, such as rivers and lake, but does not include smaller bodies of water, such as ponds and wetlands. The following SMR coolant water technologies are under consideration for use with suitable sites far from surface water sources.

Dry cooling - this technology requires low volumes of water for cooling. Although it has high operation costs and produces less power, it offers an alternative when no water supply exists [24]. Dry cooling is less efficient in hot weather.

Wet/dry cooling - this technology needs more water than dry cooling and less water than wet cooling. Wet/dry cooling can be operated in different modes based on water availability and the season [24].

Cooling towers-this technology, which relies on fans that draw moist air to the top of the tower and discharge it to the surface, is preferred for SMRs using wet cooling [24].

Cooling ponds and reservoirs-this technology uses evaporation from surface water bodies to consume heat [24].

Dry cooling, using a tower with a closed-cooling operation, has several benefits, including minimizing the water impacts from any water intake and allowing more flexibility in siting. Surface water is also a liability for SMR siting due to the risk of watershed and fisheries contamination. A 3-km buffer zone, therefore, was applied in the Open case to protect these areas (Table 4). Pipelines to supply the reactor with water from nearby lakes and rivers are also possible options. Both buffer zones and pipelines help minimize the potential for surface water contaminations and hazard.

The assignment of weighting criteria is a sensitive issue in siting studies, as experts, with their unique perspectives, can have biased value judgments and opinions about the relative importance of criteria. Examining the rationales for different weights enables seeing how the sensitivity of some criteria impacts the overall decision. For example, geological experts might evaluate criterion through a geographic lens and give prominence to geologic criteria. Taking the average of experts' criteria weights can ensure their accuracy, as the weights directly influence the final results. Figure $7 \mathrm{a}, \mathrm{b}$ on the Open case, for example, shows that the impacts of the weights for the evaluation criteria are small due to the small variation in the ratio of weights between criteria. A high ratio of weights between criteria will likely be reflected in comparably high impacts.

Some suitable sites for SMRs were selected as examples to validate our analysis (Figure 9). The selected sites were taken from the Open case final map with the first evaluation criteria weights applied. The selected sites are in proximity to populated areas and accessible to most major utilities, such as highways, transmission lines, railways, and surface water. It is clear that the potential sites are accessible to the major utilities within 0 to $5 \mathrm{~km}$, which is reasonable. Taken together, the examples from various sections of the study area offer a clear picture of some areas of the study area. 


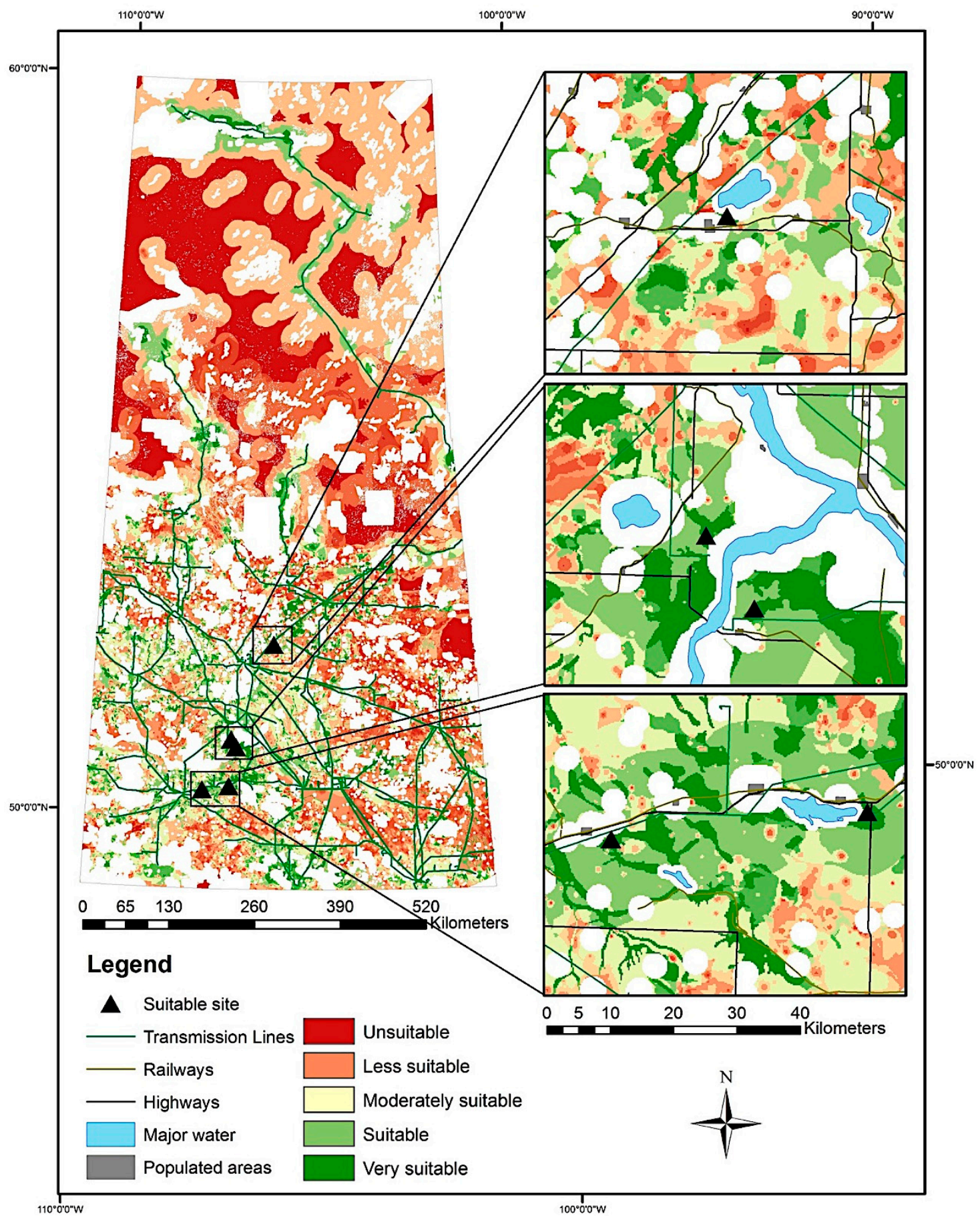

Figure 9. Example of suitable SMR sites.

\section{Conclusion and Recommendations}

The site selection criteria and data standardization methods applied in this study are suitable for SMRs across reactor types, sizes, and purposes. The study design allows changing the criteria according to design conditions and geographic considerations.

The range of suitable SMR sites is based on objective data: Quantifiable, measurable, and, specifically, geographical criteria. The analysis does not include land availability, public perceptions, or other differences that might influence site decisions. These factors can be explored in further studies. Most suitable sites are in southern Saskatchewan. This region has more accessible utility infrastructure and populated areas, which are both preferable for SMR siting. 
The criteria considered in this study fit the geographic aspect of SMR site suitability for Saskatchewan based on CNSC [7,19-21] regulations and a review of the relevant literature. The criteria can be modified to consider reactor types, sizes, and vendor requirements. The weightings criteria were applied only for demonstration purposes and can be further refined based on experts' opinions. Fuzzy standardization criteria fit the geographic spatial measurements for Saskatchewan. The three cases conform to the trends of government perspectives, which can change once projects are in process. More detailed topics that could be explored in future research include public perceptions of nuclear reactors, energy supply and demand, and other topics unrelated to geography. Future studies should explore the potentials and limitations for siting SMRs in northern regions.

To conclude, this research presents a general case for geographical considerations of siting SMRs in Saskatchewan. It can be further refined by considering specific reactor types and sizes.

Author Contributions: Conceptualization, R.A., J.P., and J.S.; methodology, R.A.; software, R.A.; validation, J.P. and J.S.; formal analysis, R.A.; investigation, R.A.; resources, R.A.; data curation, R.A.; writing-original draft preparation, R.A.; writing-review and editing, J.P. and J.S.; visualization, J.S.; supervision, J.P.; project administration, R.A.; funding acquisition, J.P.

Funding: This research received financial support from the Sylvia Fedoruk Canadian Centre for Nuclear Innovation and Umm Al-Qura University.

Acknowledgments: I would like to express my sincere gratitude to Esam Hussein for his insightful comments and encouragement.

Conflicts of Interest: The authors declare no conflicts of interest.

\section{References}

1. Tarlton, S. Nuclear Energy in the 21st Century. The World Nuclear University Primer; Elesvier and World Nuclear Unicersity: London, UK, 2012.

2. SaskPower. SaskPower 2014 Annual Report; SaskPower: Regina, SK, Canada, 2014.

3. SaskPower. Powering Saskatchewan to a Cleaner Energy Future; SaskPower: Regina, SK, Canada, 2016-17.

4. Environment Canada. National Inventory Report; Environment Canada: Gatineau, QC, Canada, 2014. Available online: http://www.environment.gov.sk.ca/climatechange (accessed on 23 October 2017).

5. Saskatchewan Ministry of the Economy. Minerals Industry. 2015. Available online: http://publications.gov. sk.ca/documents/310/93218-Minerals\%20Industry\%202016.pdf (accessed on 6 May 2017).

6. World Nuclear Association. Nuclear Power in Sweden. 2017. Available online: http://www.world-nuclear. org/information-library/country-profiles/countries-o-s/sweden.aspx (accessed on 2 August 2017).

7. Canadian Nuclear Safety Commission. DIS-16-04, Small Modular Reactors: Regulatory Strategy, Approaches and Challenges. Canadian Nuclear Safety Commission, 2016. Available online: http://nuclearsafety.gc.ca/ eng/acts-and-regulations/consultation/comment/d-16-04/index.cfm (accessed on 1 July 2017).

8. Rodman, L.; Hartman, K. New Nuclear Power Plant Designs: The Not So Small Role of Small Modular Reactors. 8 December 2015. Available online: http://www.ncsl.org/research/energy/nuclear.aspx (accessed on 29 January 2018).

9. Lyons, P. Small Modular Reactors; Bipartisan Policy Center: Washington, DC, USA, 2012.

10. Belles, R.; Omitaomu, O. Population Sensitivity Evaluation of Two Candidate Locations for Possible Small Modular Reactor Siting Study; Oak Ridge National Laboratory: Oak Ridge, TN, USA, 2014; ORNL/TM-2014/300.

11. Al-Hanbali, A.; Alsaaideh, B.; Kondoh, A. Using GIS-Based Weighted Linear Combination Analysis and Remote Sensing Techniques to Select Optimum Solid Waste Disposal Sites within Mafraq City, Jordan. J. Geogr. Inf. Syst. 2011, 3, 267-278. [CrossRef]

12. Huang, I.B.; Keisler, J.; Linkov, I. Multi-criteria decision analysis in environmental sciences: Ten years of applications and trends. Sci. Total. Environ. 2011, 409, 3578-3594. [CrossRef] [PubMed]

13. Li, C.; Annisa, A.; Zaman, A.; Qaosar, M.; Ahmed, S.; Morimoto, Y. MapReduce Algorithm for Location Recommendation by Using Area Skyline Query. Algorithms 2018, 11, 191. [CrossRef]

14. Annisa, A.; Zaman, A.; Morimoto, Y. Area Skyline Query for Selecting Good Locations in a Map. J. Inf. Process. 2016, 24, 946-955. [CrossRef] 
15. Rikalović, A.; Cosic, I.; Lazarevic, D. GIS Based Multi-criteria Analysis for Industrial Site Selection. Procedia Eng. 2014, 69, 1054-1063. [CrossRef]

16. Environment and Climate Change Canada. Greenhouse Gas Emissions by Province and Territory. 13 April 2017. Available online: https://www.ec.gc.ca/indicateurs-indicators/default.asp?lang=en\&n=18F3BB9C-1 (accessed on 23 October 2017).

17. Lewry, M. Encylopedia of Saskatchewan. 14 March 2016. Available online: http://esask.uregina.ca/entry/ saskatchewan.html (accessed on 2 July 2017).

18. The Canadian Encyclopedia. Saskatchewan. 10 August 2017. Available online: http://www. thecanadianencyclopedia.ca/en/article/saskatchewan/ (accessed on 9 April 2017).

19. Canadian Nuclear Safety Commission. Licensing Process for New Nuclear Power Plants in Canada. Canadian Nuclear Safety Commission, August 2008. Available online: http://nuclearsafety.gc.ca/pubs_catalogue/ uploads/I0756_R1_e.pdf (accessed on 29 January 2018).

20. Canadian Nuclear Safety Commission. RD-346: Site Evaluation for New Nuclear Power Plants. Canadian Nuclear Safety Commission, 2008. Available online: http://nuclearsafety.gc.ca/eng/acts-and-regulations/ regulatory-documents/published/html/rd346/ (accessed on 23 April 2017).

21. Canadian Nuclear Safety Commission. Design of New Nuclear Power Plants. Canadian Nuclear Safety Commission, November 2008. Available online: http://nuclearsafety.gc.ca/pubs_catalogue/uploads/RD-337_ e.pdf (accessed on 29 January 2018).

22. Gigovic, L.; Pamucar, D.; Bajic, Z.; Milicevic, M. The Combination of Expert Judgment and The Combination of Expert Judgment and Sites for Ammunition Depots. Sustainability 2016, 8, 372. [CrossRef]

23. Idaho National Laboratory. Site Suitability and Hazard Assessment Guide for Small Modular Reactors; Idaho National Laboratory: Idaho Falls, ID, USA, 2013; INL/EXT-13-29749.

24. Golder Associates. Small Modular Reactors an Analysis of Factors Related to Siting and Licensing in Washington State; Washington State Energy Facility: Washington, DC, USA, 2016.

25. IAEA. Managing Siting Activities for Nuclear Power Plants; International Atomic Energy Agency: Vienna, Austria, 2012; No NG-T-3.7.

26. Golder Associates. Annex II-Geology and Hydrogeology Baseline Report; Golder Associates: Regina, SK, Canada, 2014; 10-1365-0004/DCN-072.

27. Everitt, R.; McMurray, J.; Brown, A.; Davison, C. Geology of the Lac du Bonnet Batholith, Inside and Out: AECL's Underground Research Laboratory, Southeastern Manitoba; Joint Annual Meeting 27-29 MAY/MAI 1996; Geological Association of Canada: Winnipeg, MB, Canada, 1996.

28. Drobne, S.; Lisec, A. Multi-attribute Decision Analysis in GIS: Weighted Linear Combination and Ordered Weighted Averaging. J. Fac. Eng. Archit. Gazi Univ. 2009, 33, 459-474.

29. Saaty, T.L. Decision making with the analytic hierarchy process. Int. J. Serv. Sci. 2008, 1, 83-97. [CrossRef]

30. Fam, F.; Usama, H.; Yehia, H.; Emad, A. Applying decision-making techniques to Civil Engineering Projects. Sci. Direct 2017, 6, 327-328.

31. Ishizaka, A.; Labib, A. Review of the main developments in the analytic hierarchy process. Expert Syst. Appl. 2011, 38, 14336-14345. [CrossRef]

32. Belles, R.; Mays, G.; Omitaomu, O.; Poore, W. Updated Application of Spatial Data Modeling and Geographical Information Systems (GIS) for Identification of Potential Siting Options for Small Modular Reactors; Department of Energy (DOE) Information Bridge, UT-battlle: Oak Ridge, TN, USA, 2012; ORNL/TM-2011/157/R1.

33. Lyman, E. Small Isn't Always Beautiful Safety, Security, and Cost Concerns about Small Modular Reactors. Union of Concerned Scientists, 2013. Available online: https://www.ucsusa.org/sites/default/files/legacy/ assets/documents/nuclear_power/small-isnt-always-beautiful.pdf (accessed on 2 July 2017).

(C) 2019 by the authors. Licensee MDPI, Basel, Switzerland. This article is an open access article distributed under the terms and conditions of the Creative Commons Attribution (CC BY) license (http://creativecommons.org/licenses/by/4.0/). 